OPEN ACCESS

Edited by:

Guang $\mathrm{Hu}$,

Soochow University, China

Reviewed by:

Jian Tian,

Chinese Academy of Agricultural

Sciences, China

Hao Dong,

Nanjing University, China

${ }^{*}$ Correspondence:

Hua Yin

yinhua@tsingtao.com.cn

Specialty section:

This article was submitted to Biological Modeling and Simulation, a section of the journal

Frontiers in Molecular Biosciences

Received: 02 December 2019

Accepted: 16 March 2020

Published: 16 April 2020

Citation:

Du J, Dong J, Du S, Zhang K,

Yu J, Hu S and Yin H (2020)

Understanding Thermostability

Factors of Barley Limit Dextrinase by

Molecular Dynamics Simulations.

Front. Mol. Biosci. 7:51.

doi: $10.3389 /$ fmolb.2020.00051

\section{Understanding Thermostability Factors of Barley Limit Dextrinase by Molecular Dynamics Simulations}

\author{
Juan Du ${ }^{1,2}$, Jianjun Dong ${ }^{1}$, Songjie $\mathrm{Du}^{2}$, Kun Zhang ${ }^{2}$, Junhong $\mathrm{Yu}^{1}$, Shumin $\mathrm{Hu}^{1}$ and \\ Hua Yin ${ }^{1 *}$ \\ ${ }^{1}$ State Key Laboratory of Biological Fermentation Engineering of Beer, Tsingtao Brewery, Qingdao, China, ${ }^{2}$ Shandong \\ Province Key Laboratory of Applied Mycology, College of Life Sciences, Qingdao Agricultural University, Qingdao, China
}

Limit dextrinase (LD) is the only endogenous starch-debranching enzyme in barley (Hordeum vulgare, Hv), which is the key factor affecting the production of a high degree of fermentation. Free LD will lose its activity in the mashing process at high temperature in beer production. However, there remains a lack of understanding on the factor affecting the themostability of HVLD at the atomic level. In this work, the molecular dynamics simulations were carried out for HVLD to explore the key factors affecting the thermal stability of LD. The higher value of root mean square deviation (RMSD), radius of gyration $\left(R_{g}\right)$, and surface accessibility (SASA) suggests the instability of HvLD at high temperatures. Intra-protein hydrogen bonds and hydrogen bonds between protein and water decrease at high temperature. Long-lived hydrogen bonds, salt bridges, and hydrophobic contacts are lost at high temperature. The salt bridge interaction analysis suggests that these salt bridges are important for the thermostability of $H v L D$, including E568-R875, D317-R378, D803-R884, D457-R214, D468-R395, D456-R452, D399R471, and D541-R542. Root mean square fluctuation (RMSF) analysis identified the thermal-sensitive regions of $H v L D$, which will facilitate enzyme engineering of $H v L D$ for enhanced themostability.

Keywords: barley limit dextrinase, thermostability, molecular dynamics simulation, hydrogen bond, salt-bridge

\section{INTRODUCTION}

Limit dextrinase (LD), also termed R-enzyme, pullulanase, isoamylase, or amylopectin 6glucanohydrolase, is the only endogenous starch-debranching enzyme in barley (Hordeum vulgare, $H v$ ) that digests amylopectin and dextrins (Manners et al., 1970; Yang et al., 2008). HvLD belongs to the glycoside hydrolase family 13 subfamily 13 (GH13_13) and can cleave $\alpha$-1,6-glucosidic bonds in limit dextrins derived from amylopectin (Stam et al., 2006).

Barley is a major raw material in beer production. The major biochemical process in brewing is to degrade barley starch into fermentable sugars, which are further converted into alcohol by yeast metabolism. $H v \mathrm{LD}$ as a specific enzyme to digest amylopectin and dextrins is the key factor affecting the production of a high degree of fermentation (Wang et al., 2015). There are three different forms of LD existing in barley: insoluble bound, soluble inactive, and active free. Only the free form is capable for degrading amylopectin (Sissons et al., 1994). The essential industrial process 
of brewing includes three steps: malting, mashing, and fermentation. Mashing is usually performed at $60-70^{\circ} \mathrm{C}$ and at a pH of below 4.5 (Moshi et al., 2015). The heat resistance of $\mathrm{LD}$ in free form is poorer than the bound or latent form (Sissons et al., 1995). Free LD will lose its activity in the mashing process at a temperature higher than $63^{\circ} \mathrm{C}$ (Sissons et al., 1995). High themostability and activity of LD is desirable for the beer production.

Several crystal structures of $H v \mathrm{LD}$ have been reported (VesterChristensen et al., 2010; Møller et al., 2012a, Møller et al., 2015a,b). The HvLD structure contains four domains (VesterChristensen et al., 2010) (shown in Figure 1): the N-terminal domain, a carbohydrate binding module 48 (CBM48), a catalytic $(\beta / \alpha) 8$ domain containing the two catalytic residues (Asp473, nucleophile; Glu510, general acid/base) and the transition-state stabilizer (Asp642), and a C-terminal domain. The N-terminal domain includes residues 2-124 resembling carbohydrate binding module 21. CBM48 includes residues 125-230. The catalytic domain contains residues 231-774 and the C-terminal domain contains residues 775-885.

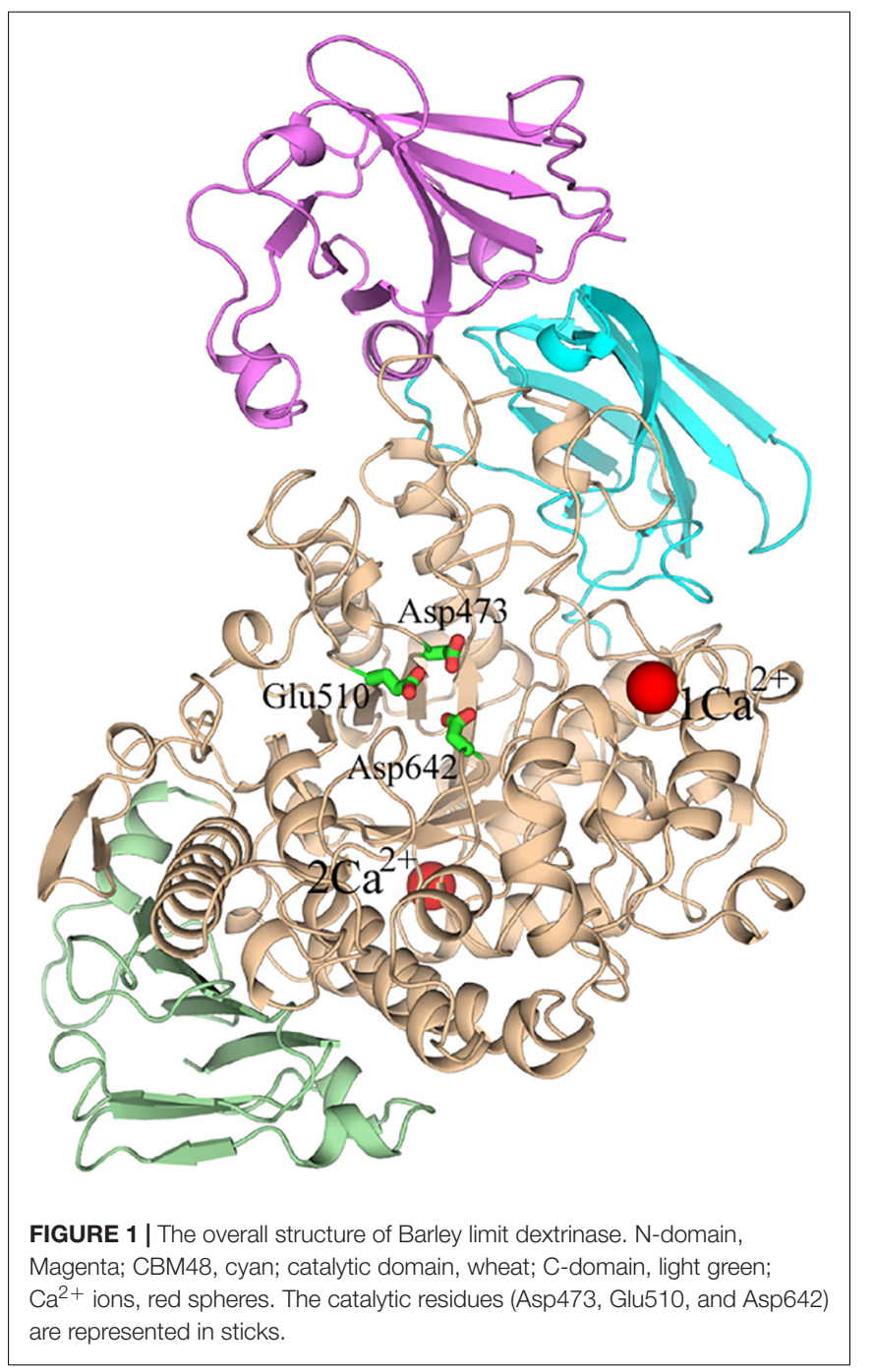

There are several works focused on improvement of the themostability of pullulanase derived from bacteria (Chen et al., 2015; Li et al., 2015; Chang et al., 2016; Wang et al., 2016). However, it is still lacking the understanding on the factor affecting the themostability of $H \nu \mathrm{LD}$ at the atomic level. It is suggested that enzymes keep their structural stability by various kinds of non-covalent interactions, such as hydrogen bonds, salt bridges, disulfide bonds, and hydrophobic interaction (Nick Pace et al., 2014; Nilofer et al., 2017). Recently, molecular dynamics (MD) simulation, as a useful tool, has been widely applied to find important characteristics of protein stability (Alizadeh-Rahrovi et al., 2015; Sharma and Sastry, 2015; Jiang et al., 2016; Idrees et al., 2017; Gu et al., 2019).

In this work, MD simulations were carried out for barley limit dextrinase $(H v \mathrm{LD})$ to explore the key factors affecting the thermal stability of LD. The root mean square deviation (RMSD), radius of gyration $\left(R_{\mathrm{g}}\right)$, and surface accessibility (SASA) were calculated to explore the dynamics of $H v \mathrm{LD}$. Intra-protein hydrogen bonds, protein-water hydrogen bonds, salt bridges, and hydrophobic interaction were analyzed to find the factors about the thermal stability of $H v$ LD. Finally, root mean square fluctuation (RMSF) analysis was performed to identify the thermal-sensitive regions of LD. The structural and dynamic details will help to understand the driving forces that lead to the stability of $H v \mathrm{LD}$ at different temperatures, which will facilitate enzyme engineering of $H v \mathrm{LD}$.

\section{MATERIALS AND METHODS}

\section{Systems Preparation}

The X-ray structure of barley LD (PDB ID: 4CVW) (Møller et al., 2015a) was obtained from the RCSB Protein Data Bank. The LD inhibitor was removed from this structure. The structure of barley LD (PDB ID: 4CVW) was superimposed on the free form of HvLD (PDB ID: 4AIO) (Møller et al., 2012b). The missing residues (43-PSN-45, 102-FGADGK-107) were also built based on the coordinate of the corresponding residues in the free form of HvLD (PDB ID: 4AIO). A mutant of $\mathrm{LD}^{\mathrm{D} 317 \mathrm{~A}}$ was constructed to evaluate the effect of salt bridge between Asp317 and Arg378.

\section{Simulations}

Standard AMBER ff03 force field (Wang et al., 2004; Hornak et al., 2006) was assigned to the protein. The force field parameter developed by Bradbrook et al. (1998) was assigned for the $\mathrm{Ca}^{2+}$. The protonation state of ionizable residues was set under $\mathrm{pH} 5.5$ based on the pKa values calculated by the $\mathrm{H}++$ server (Anandakrishnan et al., 2012). $\mathrm{Na}^{+}$ions were added to neutralize the overall system. Each system was embedded in a rectangular box of the TIP3P water molecule (Jorgensen et al., 1983), maintaining a distance of $10 \AA$ from any solute atom to the boundary.

The MD simulations were performed using AMBER12. Energy minimization was carried out with a decreasing harmonic force constraint on the protein. The minimized system was gradually heated from $0 \mathrm{~K}$ to the desired temperature within 200 ps under the NVT ensemble condition. The temperature was set as $298 \mathrm{~K}, 318 \mathrm{~K}$ (optimum temperature), and $343 \mathrm{~K}$ (the 
highest mashing temperature), respectively. To investigate the effect of calcium ions for the structural stability, three systems without $\mathrm{Ca}^{2+}$ at 298, 318, and $343 \mathrm{~K}$ were also constructed. The temperature was set as 298 and $343 \mathrm{~K}$ for $\mathrm{LD}^{\mathrm{D} 317 \mathrm{~A}}$. Then, the system was relaxed within 1.55 ns under the NPT ensemble condition. Finally, a total of $100 \mathrm{~ns}$ was simulated to produce trajectories under the NPT ensemble condition for each system. A 50-ns MD simulation was conducted for $\mathrm{LD}^{\mathrm{D} 317 \mathrm{~A}}$ at both temperatures. The covalent bonds to hydrogen atoms were constrained using the SHAKE algorithm (Coleman et al., 1977) and the Particle Mesh Ewald (PME) method (Darden et al., 1993) was employed to calculate long-range electrostatic interactions. The real space cutoff was set at $10.0 \AA$, the same as that for van der Waals interactions. The grid-spacing and convergence criteria of PME calculation was set to $1 \AA$ and $1.0 \mathrm{E}-05$, respectively. The time step used for the simulations was set to $2 \mathrm{fs}$. The atom coordinates were saved every $10 \mathrm{ps}$ for subsequent analysis.

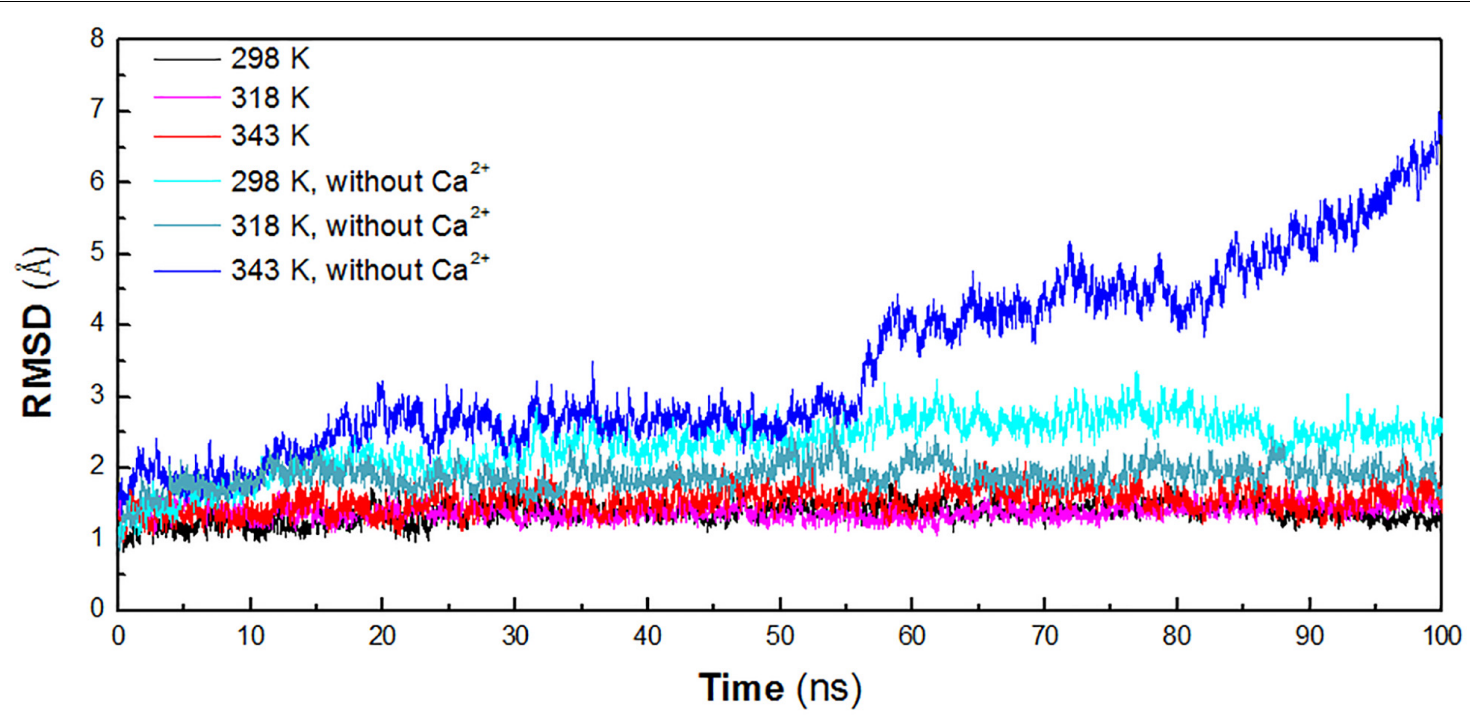

FIGURE 2 | Time evolution of the backbone RMSD versus the starting structure of HVLD. The simulation data obtained at 298, 318, 343, $298 \mathrm{~K}$, without Ca ${ }^{2+}$, $318 \mathrm{~K}$ without $\mathrm{Ca}^{2+}$, and $343 \mathrm{~K}$ without $\mathrm{Ca}^{2+}$ are shown in black, magenta, red, cyan, deep teal, and blue, respectively.

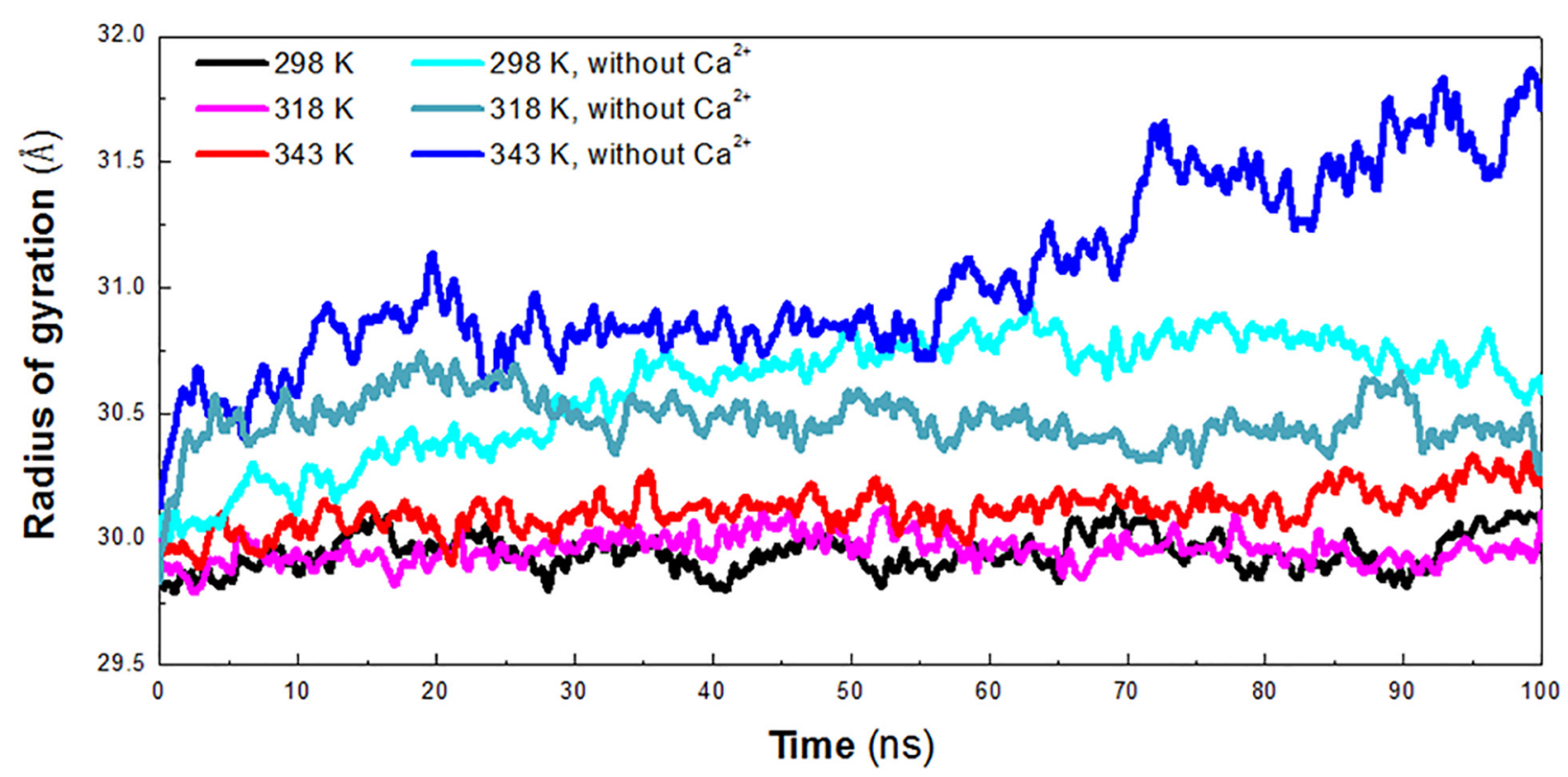

FIGURE 3 | Radius of gyration $\left(R_{\mathrm{g}}\right)$ plot. The simulation data obtained at $298 \mathrm{~K}, 318 \mathrm{~K}, 343 \mathrm{~K}, 298 \mathrm{~K}$ without $\mathrm{Ca}^{2+}, 318 \mathrm{~K}$ without $\mathrm{Ca}^{2+}$, and $343 \mathrm{~K}$ without $\mathrm{Ca}^{2+}$ is shown in black, magenta, red, cyan, deep teal, and blue, respectively. 


\section{Analysis}

All of the analyses were performed using the analytical tools cpptraj (Roe and Cheatham, 2013) module in AMBER tools and VMD (Humphrey et al., 1996). The RMSD was calculated as the deviation between backbone atoms of the protein with respect to the initial structure's backbone atoms, averaged over the backbone atoms. For the RMSF and SASA, the average value was calculated over time. SASA was calculated for all of the residues, hydrophobic residues, hydrophilic residues, and catalytic residues (Asp473, Glu510, and Asp642), respectively. The $R_{\mathrm{g}}$ was calculated by VMD.

The hydrogen bond was calculated based on a maximum cutoff distance between the donor and the acceptor at $3.5 \AA$ and the angle of donor-hydrogen-acceptor larger than $120^{\circ}$. The average value of the number of hydrogen bond was calculated as the ratio of the sum of the total number of HBs in each frame to the total number of frames. The redundant hydrogen bonds between the same donor and acceptor but with different hydrogen atoms were removed, saving the one with the highest occupancy. The HBs were analyzed by considering the chemical properties of different residues, including charged residues (Arg, Lys, Asp, and Glu), polar residues (Gln, Asn, Ser, Thr, Tyr, and Cys), and hydrophobic residues (Ala, Ile, Leu, Phe, Val, Pro, Gly, Met, and Trp).

The salt bridges (SBs) were considered to be formed if the distance between an oxygen atom of an acidic residue $(\mathrm{O} \delta 1$ and $\mathrm{O} \delta 2$ of ASP and $\mathrm{O} \delta 1$ and $\mathrm{O} \delta 2$ of Glu) and the nitrogen atom of a basic residue ( $\mathrm{N} \varepsilon, \mathrm{N} \eta 1$ and $\mathrm{N} \eta 2$ of Arg and $\mathrm{N} \zeta$ of Lys) was less than $4 \AA$. The average value of the number of SBs was calculated as the ratio of the sum of the total number of SBs in each frame to the total number of frames. The SBs between the same two residues but different atoms were regarded as unique, keeping the one with the highest occupancy.

It is suggested that all C atoms within $3.9 \AA$ interacts through hydrophobic contacts (Stojanovic and Zaric, 2009). We calculated the hydrophobic contacts between all the hydrophobic atoms $(\mathrm{C}, \mathrm{C} \alpha, \mathrm{C} \beta, \mathrm{C} \delta, \mathrm{C} \delta 1, \mathrm{C} \delta 2, \mathrm{C} \varepsilon, \mathrm{C} \varepsilon 1, \mathrm{C} \varepsilon 2, \mathrm{C} \varepsilon 3, \mathrm{C} \gamma, \mathrm{C} \gamma 1$, $\mathrm{C} \gamma 2, \mathrm{C} \zeta, \mathrm{C} \zeta 2, \mathrm{C} \zeta 3$, and $\mathrm{C} \eta 2$ ) with a cutoff of $4 \AA$, without redundancy. The structures were visualized by VMD and PyMOL (Schrödinger, 2010).

A one-way ANOVA was conducted here to evaluate whether the differences are significant for systems containing $\mathrm{Ca}^{2+}$, $318 \mathrm{~K} / 298 \mathrm{~K}$ and $343 \mathrm{~K} / 298 \mathrm{~K}$, and systems without $\mathrm{Ca}^{2+}$ $\left(318 \mathrm{~K} / 298 \mathrm{~K}\right.$ and $343 \mathrm{~K} / 298 \mathrm{~K}$ ) for the RMSD, $R_{\mathrm{g}}$, and SASA. The difference is considered significant in the case of $P<0.05$.

\section{RESULTS AND DISCUSSION}

\section{Dynamics of Barley LD}

In order to identify the key factors responsible for instability of $H v \mathrm{LD}$ at high temperature, $\mathrm{MD}$ simulations were performed at different temperature conditions $(298,318$, and $343 \mathrm{~K})$ to predict the molecular behavior over the period of time using AMBER. To
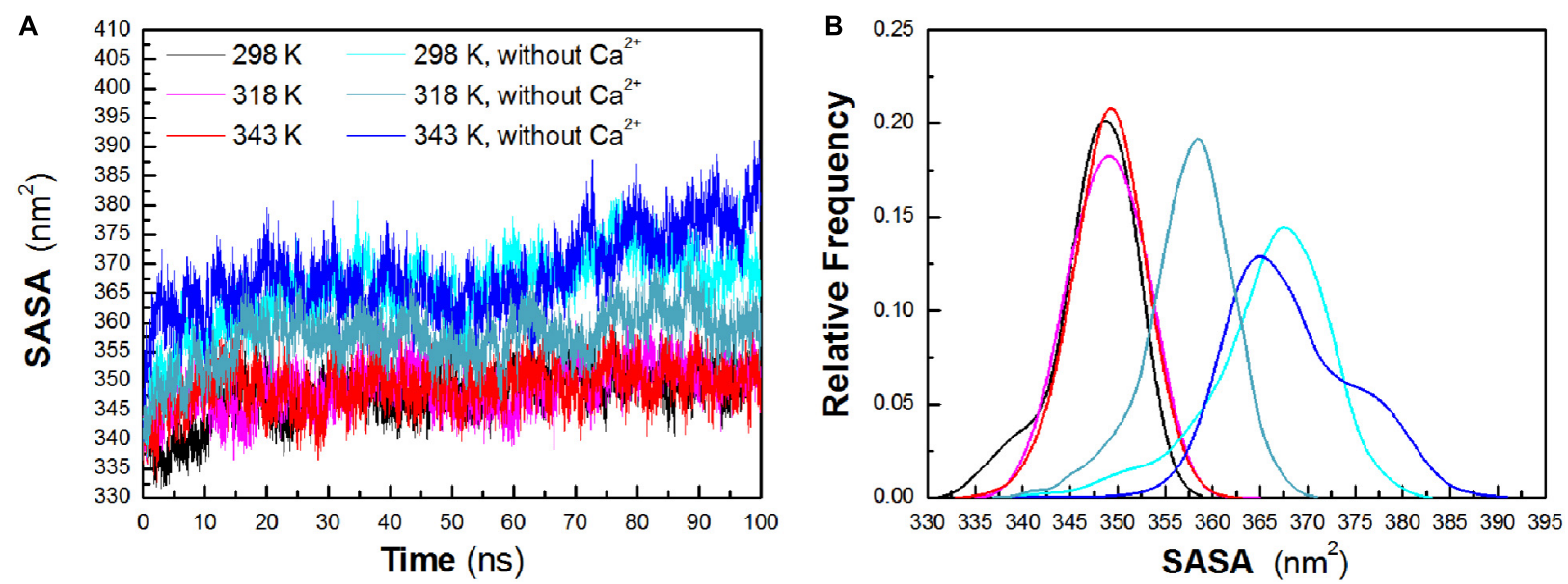

FIGURE 4 | Total solvent-accessible surface area (SASA). (A) Time evolution of total SASA. (B) The distribution of total SASA. The simulation data obtained at 298, $318,343,298 \mathrm{~K}$ without $\mathrm{Ca}^{2+}, 318 \mathrm{~K}$ without $\mathrm{Ca}^{2+}$, and $343 \mathrm{~K}$ without $\mathrm{Ca}^{2+}$ are shown in black, magenta, red, cyan, deep teal, and blue, respectively.

TABLE 1 | Average value of SASA in different systems.

\begin{tabular}{|c|c|c|c|c|}
\hline Systems & SASA $_{\text {pho }}$ & SASA $_{\text {phil }}$ & SASA $_{\text {total }}$ & SASA $_{\text {catalytic }}$ \\
\hline $298 K$ & $110.48 \pm 2.87$ & $237.15 \pm 2.52$ & $347.63 \pm 4.29$ & $60.32 \pm 7.83$ \\
\hline $318 \mathrm{~K}$ & $111.56 \pm 1.98$ & $237.34 \pm 2.81$ & $348.90 \pm 3.95$ & $61.81 \pm 6.90$ \\
\hline $343 \mathrm{~K}$ & $110.05 \pm 2.18$ & $239.00 \pm 2.81$ & $349.05 \pm 3.78$ & $65.57 \pm 7.34$ \\
\hline 298 K, no $\mathrm{Ca}^{2+}$ & $114.29 \pm 3.16$ & $251.51 \pm 4.05$ & $365.80 \pm 6.52$ & $67.34 \pm 8.36$ \\
\hline $318 \mathrm{~K}, \mathrm{no} \mathrm{Ca}^{2+}$ & $111.15 \pm 2.05$ & $246.28 \pm 3.30$ & $357.43 \pm 4.75$ & $71.56 \pm 9.25$ \\
\hline $343 \mathrm{~K}$, no $\mathrm{Ca}^{2+}$ & $116.19 \pm 2.67$ & $252.08 \pm 4.91$ & $368.26 \pm 6.79$ & $71.88 \pm 8.14$ \\
\hline
\end{tabular}


investigate the effect of calcium ions for the structural stability, MD simulations were also conducted for the three systems without $\mathrm{Ca}^{2+}(298,318$, and $343 \mathrm{~K})$. The structural stability of six systems was examined by calculation of the RMSD of the backbone atoms relative to the initial structure. Figure 2 shows the RMSD variations of the six systems with respect to simulation time. It is observed that the systems are equilibrated and thus suitable for exploring the dynamics of $H v L D$. The first three systems achieved equilibrium at 20,10, and 25 ns, respectively.
The RMSD values for the backbone atoms of $H v L D$ converge at $1.40 \pm 0.11$ and $1.39 \pm 0.10 \AA$ at 298 and $318 \mathrm{~K}$ and $1.59 \pm 0.16 \AA$ at $343 \mathrm{~K}$. The statistical analysis suggests that the differences are significant $(P<0.05)$ (Supplementary Table S1). HvLD in the systems without $\mathrm{Ca}^{2+}$ exhibits large variation compared with the initial structure at 298 and $343 \mathrm{~K}$. The backbone RMSD increases rapidly and major structural distortion occurs at $343 \mathrm{~K}$.

The radius of gyration $\left(R_{\mathrm{g}}\right)$ reflects the compactness of protein structure. To detect the compactness of the overall structure, the

TABLE 2 | Average numbers of hydrogen bonds in different systems.

\begin{tabular}{|c|c|c|c|c|c|c|c|c|}
\hline Systems & $\begin{array}{c}\text { Total } \\
\text { HB }\end{array}$ & $\begin{array}{l}\text { MM } \\
\text { HB }^{a}\end{array}$ & $\begin{array}{c}\text { MS } \\
\text { HB }^{b}\end{array}$ & $\begin{array}{c}\text { SS } \\
H^{c}\end{array}$ & $\begin{array}{c}\text { chr-chr } \\
H^{\prime} B^{d}\end{array}$ & $\begin{array}{c}\text { pho-pho } \\
\text { HB }^{\mathrm{e}}\end{array}$ & $\begin{array}{c}\text { phi-phi } \\
\text { HB }^{f}\end{array}$ & $\begin{array}{c}\text { pho-phi } \\
\text { HB }^{\mathrm{g}}\end{array}$ \\
\hline $298 \mathrm{~K}$ & 756.05 & 283.61 & 178.40 & 171.83 & 99.54 & 130.50 & 74.05 & 207.83 \\
\hline $318 \mathrm{~K}$ & 776.17 & 297.84 & 175.45 & 169.51 & 104.83 & 136.48 & 72.03 & 207.73 \\
\hline $343 \mathrm{~K}$ & 720.27 & 265.37 & 175.74 & 166.44 & 91.80 & 127.46 & 73.69 & 206.42 \\
\hline 298 K, no $\mathrm{Ca}^{2+}$ & 754.33 & 295.91 & 178.82 & 150.73 & 81.55 & 140.52 & 74.21 & 204.34 \\
\hline $318 \mathrm{~K}, \mathrm{no} \mathrm{Ca}^{2+}$ & 732.57 & 283.64 & 171.22 & 154.77 & 82.36 & 133.26 & 73.05 & 205.53 \\
\hline $343 \mathrm{~K}, \mathrm{no} \mathrm{Ca}^{2+}$ & 745.39 & 287.05 & 174.38 & 155.38 & 90.66 & 138.89 & 66.77 & 195.73 \\
\hline
\end{tabular}

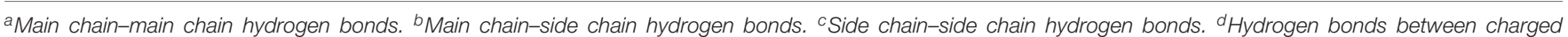

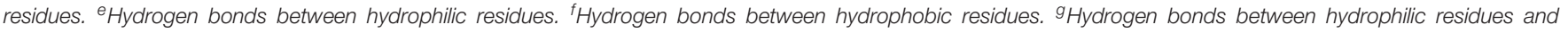
hydrophobic residues.

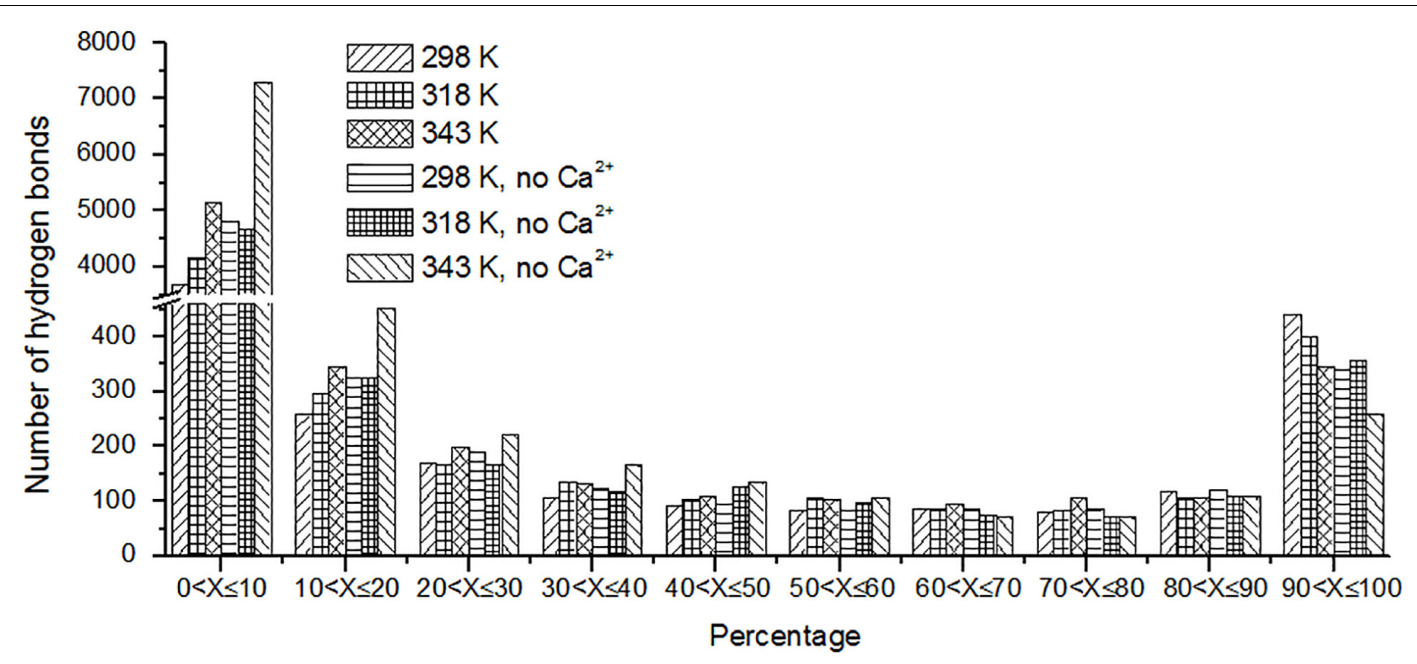

FIGURE 5 | The number of hydrogen bonds ( $y$-axis) based on percentage existence time ( $x$-axis).

TABLE 3 | Average numbers of protein-water hydrogen bonds in different systems.

\begin{tabular}{|c|c|c|c|c|c|c|}
\hline Systems & $\begin{array}{l}\text { Pro-water } \\
\text { Total } \text { HB }^{\mathbf{a}}\end{array}$ & $\begin{array}{c}\text { M-water } \\
\text { HB }^{\mathbf{b}}\end{array}$ & $\begin{array}{c}\text { S-water } \\
\text { HB }^{\mathbf{c}}\end{array}$ & $\begin{array}{c}\text { chr-water } \\
\text { HB }^{\mathrm{d}}\end{array}$ & $\begin{array}{c}\text { pho-water } \\
\text { HB }^{\mathrm{e}}\end{array}$ & $\begin{array}{c}\text { phi-water } \\
\text { HB }^{f}\end{array}$ \\
\hline $298 \mathrm{~K}$ & 928.69 & 273.55 & 655.14 & 358.89 & 243.81 & 323.87 \\
\hline $318 \mathrm{~K}$ & 925.18 & 270.69 & 654.49 & 356.18 & 239.94 & 326.95 \\
\hline $343 \mathrm{~K}$ & 894.48 & 257.36 & 637.11 & 349.38 & 227.40 & 315.66 \\
\hline 298 K, no $\mathrm{Ca}^{2+}$ & 967.29 & 275.80 & 691.49 & 390.55 & 245.21 & 329.83 \\
\hline $318 \mathrm{~K}$, no $\mathrm{Ca}^{2+}$ & 954.70 & 277.43 & 677.27 & 378.16 & 245.75 & 328.70 \\
\hline $343 \mathrm{~K}$, no $\mathrm{Ca}^{2+}$ & 924.28 & 262.96 & 661.31 & 363.69 & 237.24 & 321.18 \\
\hline
\end{tabular}

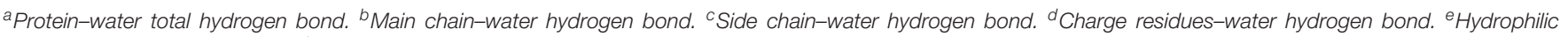
residues-water hydrogen bond. ${ }^{f}$ Hydrophobic residues-water hydrogen bond. 
radius of gyration $\left(R_{\mathrm{g}}\right)$ of the protein in six systems was also calculated, as shown in Figure 3. According to RMSD plot, all the systems converged after $25 \mathrm{~ns}$. We calculated the average $R_{\mathrm{g}}$ ranging from 25 to $100 \mathrm{~ns}$ in each system. The averaged $R_{\mathrm{g}}$ value indicated that the compactness of $H v \mathrm{LD}$ increases when the temperature rises. $H v \mathrm{LD}$ has the most compact structure at the lowest temperature $\left(298 \mathrm{~K}, R_{\mathrm{g}}: 29.95 \pm 0.09 \AA\right)$. Moreover, $H v \mathrm{LD}$ exhibits similar compactness at $318 \mathrm{~K}\left(R_{\mathrm{g}}: 29.97 \pm 0.08 \AA\right)$ and $343 \mathrm{~K}\left(R_{\mathrm{g}}: 30.14 \pm 0.09 \AA\right)$. The structure of $H v \mathrm{LD}$ is less compact at the higher temperature than it at the lower temperature, indicating expansion of protein structure at higher temperature. The $H v \mathrm{LD}$ exhibited higher $R_{\mathrm{g}}$ values at three systems without $\mathrm{Ca}^{2+}$, with the value of $30.69 \pm 0.15 \AA(298 \mathrm{~K})$, $30.47 \pm 0.10(318 \mathrm{~K})$, and $31.13 \pm 0.34 \AA$ (343 K), respectively. This result indicated that the structure of protein in the system without $\mathrm{Ca}^{2+}$ was less compact than those systems with $\mathrm{Ca}^{2+}$. In addition, with the temperature rising, the structure of $H v \mathrm{LD}$ becomes less compact.

To evaluate the exposure of protein atoms to solvent, SASA was also obtained by calculating the surface area of atom in contact with solvent molecules. From Figure $\mathbf{4 A}$, it is found

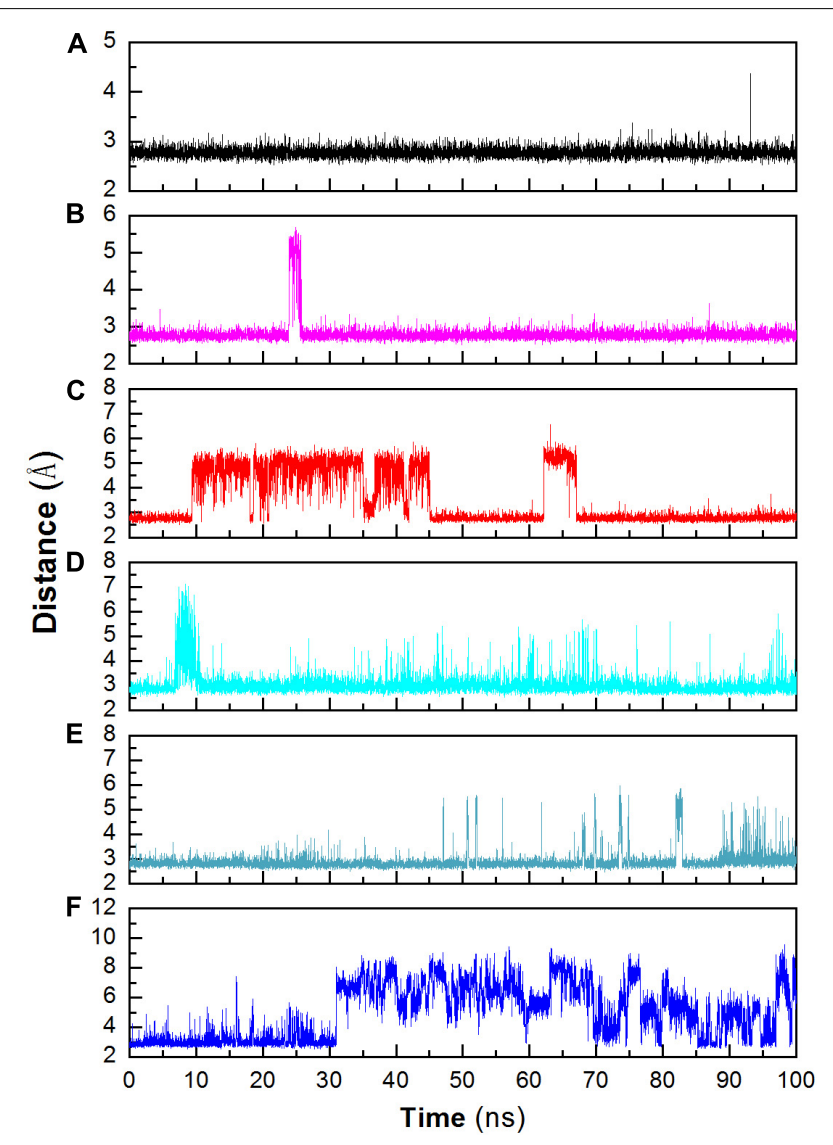

FIGURE 6 | Monitoring the hydrogen bonds between the OD1 atom of Asp403 and the ND1 atom of His404 during MD simulation. (A) $298 \mathrm{~K}$; (B) $318 \mathrm{~K}$; (C) $343 \mathrm{~K}$; (D) $298 \mathrm{~K}$ without $\mathrm{Ca}^{2+}$, (E) $318 \mathrm{~K}$ without $\mathrm{Ca}^{2+}$, (F) $343 \mathrm{~K}$ without $\mathrm{Ca}^{2+}$ that the total SASA values show a slight increase with a rise of temperature. The averaged SASA is $347.63 \pm 4.29 \mathrm{~nm}^{2}$, $348.90 \pm 3.95 \mathrm{~nm}^{2}$, and $349.05 \pm 3.78 \mathrm{~nm}^{2}$ at $298 \mathrm{~K}, 318 \mathrm{~K}$, and $343 \mathrm{~K}$, respectively, while in the systems without $\mathrm{Ca}^{2+}$, the total SASA values exhibit significant increase at both temperatures. The averaged SASA is $365.80 \pm 6.52 \mathrm{~nm}^{2}, 357.43 \pm 4.75 \mathrm{~nm}^{2}$, and $368.26 \pm 6.79 \mathrm{~nm}^{2}$ at $298 \mathrm{~K}, 318 \mathrm{~K}$, and $343 \mathrm{~K}$, respectively. Total SASA, SASA of hydrophilic residues and catalytic residues, increases relatively from $298 \mathrm{~K}$ to $343 \mathrm{~K}$ (Table 1). The distribution of SASA is displayed in Figure 4B. It can be observed that the total SASA is from 331 to $359 \mathrm{~nm}^{2}$ at $298 \mathrm{~K}$, with the major peak at $349 \mathrm{~nm}^{2}(20.73 \%)$. The same major peak appears at $318 \mathrm{~K}(18.94 \%)$ and $343 \mathrm{~K}(22.00 \%)$, respectively. In the systems without $\mathrm{Ca}^{2+}$, the total SASA increases dramatically. The range of SASA is from 337 to $383 \mathrm{~nm}^{2}$, with the major peak at $367 \mathrm{~nm}^{2}$ $(14.91 \%)$ at $298 \mathrm{~K}$. The range of SASA is from 337 to $371 \mathrm{~nm}^{2}$, with the major peak at $359 \mathrm{~nm}^{2}(18.95 \%)$ at $318 \mathrm{~K}$. The SASA at $343 \mathrm{~K}$ distributes at a range of $339-391 \mathrm{~nm}^{2}$, with the major peak at $365 \mathrm{~nm}^{2}(13.31 \%)$. This profile is consistent with the trend of $R_{\mathrm{g}}$ values, which indicates that $H v \mathrm{LD}$ become less compact with more solvent penetration into the core of the enzyme at high temperatures.

The hydrogen bond interaction is considered important in protein folding, stability, and function. It can be seen that $\mathrm{H} v \mathrm{LD}$ lost 55 hydrogen bonds at $343 \mathrm{~K}$ with respect to $298 \mathrm{~K}$ (Table 2). The number of hydrogen bonds also decreases in the systems without $\mathrm{Ca}^{2+}$. Based on the percentage existence time of HBs (Figure 5), short-lived HBs $(0<X \leq 10 \%)$ increase significantly at $343 \mathrm{~K}$, indicating that most of them appear transiently at high temperature. In contrast, the number of long-lived HBs decreases at $343 \mathrm{~K}$, indicating that these interactions are unable to maintain at high temperature. In addition, the number of substantially live HBs $(10<X \leq 90 \%)$ at $343 \mathrm{~K}$ is more than the corresponding value at $298 \mathrm{~K}$, indicating that these $\mathrm{HBs}$ contribute to the stability of $H v \mathrm{LD}$. We analyzed the HBs with occupancy higher than $50 \%$ at 298, 318, and $343 \mathrm{~K}$. There are $56 \mathrm{HBs}$ becoming weak and their occupancy decreases with the increase in temperature (Supplementary Table S2). These $\mathrm{HBs}$ are very sensitive to temperature changes and they affect the thermostability of $H v \mathrm{LD}$.

Besides, we also analyzed the effect of temperature on main chain-main chain HBs, main chain-side chain HBs, and side chain-side chain HBs. There are more MM HBs compared with two other types. There are $18 \mathrm{MM}$ HBs broken at $343 \mathrm{~K}$ compared with those at $298 \mathrm{~K}$. MM HBs are important in secondary structure formation. The decrease of the number of $\mathrm{MM} \mathrm{HBs}$ indicates that the stability of the secondary structure of the enzyme would be impaired. MS HBs and SS HBs exhibit slight decrease at $343 \mathrm{~K}$ with respect to $298 \mathrm{~K}$. Moreover, HBs among the residues having similar/different chemical properties (charged-charged residues, hydrophobichydrophobic residues, hydrophilic-hydrophilic residues, and hydrophobic-hydrophilic residues) were analyzed. Among these, the number of HBs between hydrophilic-hydrophilic residues and hydrophobic-hydrophilic residues does not exhibit a significant difference at different temperatures, while the amount 
of HBs between charged-charged residues and hydrophobichydrophobic residues reduces at $343 \mathrm{~K}$ compared with that at $298 \mathrm{~K}$. In the systems without $\mathrm{Ca}^{2+}$, the amount of the total HBs, MM HBs, MS HBs, and HBs for hydrophobichydrophobic residues, hydrophilic-hydrophilic residues, and hydrophobic-hydrophilic residues also decreases at $343 \mathrm{~K}$ compared with $298 \mathrm{~K}$. The amount of SS HBs and $\mathrm{HBs}$ for charged-charged residues increases at $343 \mathrm{~K}$ compared with $298 \mathrm{~K}$, indicating that there are new hydrogen bonds formed in the distorted structure.

The changes of HBs between protein and water were also explored in the temperature range of 298-343 K, which is displayed in Table 3. There is a decrease in protein-water HBs from 298 to $343 \mathrm{~K}$, due to the loss of both M-water HBs and S-water HBs from 298 to $343 \mathrm{~K}$. Besides, the number of HBs for hydrophobic residues to water, hydrophilic residues to water, and charged residues to water reduces at higher temperatures, indicating that the network of HBs between $H v \mathrm{LD}$ and water molecules is broken. In the systems without $\mathrm{Ca}^{2+}$, the amount of total protein-water $\mathrm{HBs}$ and other types of protein-water HBs decreases at $343 \mathrm{~K}$ compared with $298 \mathrm{~K}$, indicating the large change of the network of $\mathrm{HBs}$ between $H v \mathrm{LD}$ and water molecules in these two systems.

\section{The Stability of the Hydrogen Bond Between D403 and H404}

Structural stability may also affect the catalytic activity of this enzyme. The hydrogen bond between D403 and $\mathrm{H} 404$ is favorable for the stability of the catalytic triad, which is suggested in a previous work (Møller et al., 2015b). The distance between these two residues was monitored during the whole trajectory. It can be seen that the interaction is more stable at 298 and $318 \mathrm{~K}$ (Figure 6). When the temperature rises, the interaction becomes unstable (at $343 \mathrm{~K}$ ). In addition, most of this interaction disappeared in the system without $\mathrm{Ca}^{2+}$ at $343 \mathrm{~K}$. The unstable interaction would be unfavorable for the stability for the catalytic triad of Asp473-Glu510-Asp642.

\section{Salt Bridge Interaction Analysis}

Besides hydrogen bonds, salt bridges are also very important for the stability of protein (Horovitz et al., 1990; Strop and Mayo, 2000; Jelesarov and Karshikoff, 2009). Salt bridges in enzyme may contribute to its stability at high temperature (Vieille and Zeikus, 2001; Kundu and Roy, 2010). Recently, Guo et al. (2018) summarized factors may contribute to the thermostability for pullulan-hydrolyzing enzymes. They found that there are more

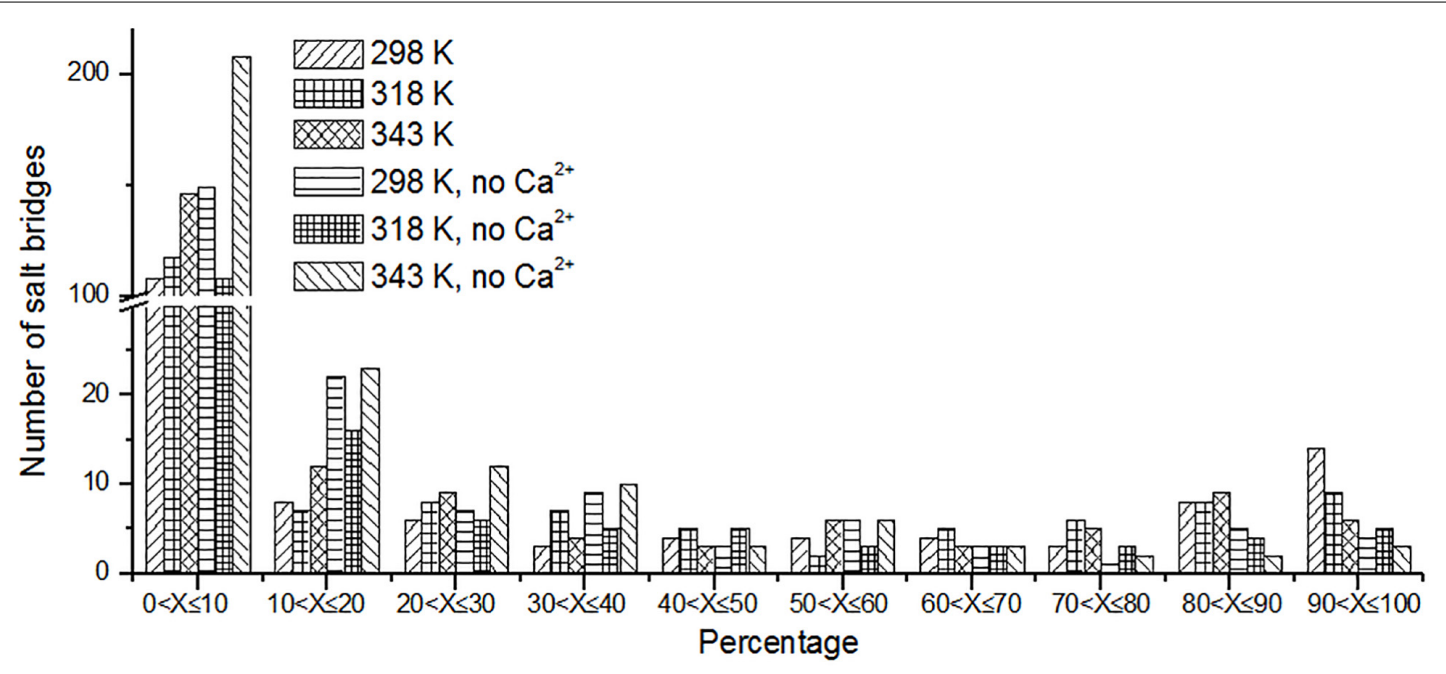

FIGURE 7 | The number of unique salt bridges based on the percentage existence time at cutoff of $4 \AA$.

TABLE 4 | Average length and occupancy of important salt bridge interactions of $H v L D$ at 298, 318, and $343 \mathrm{~K}$.

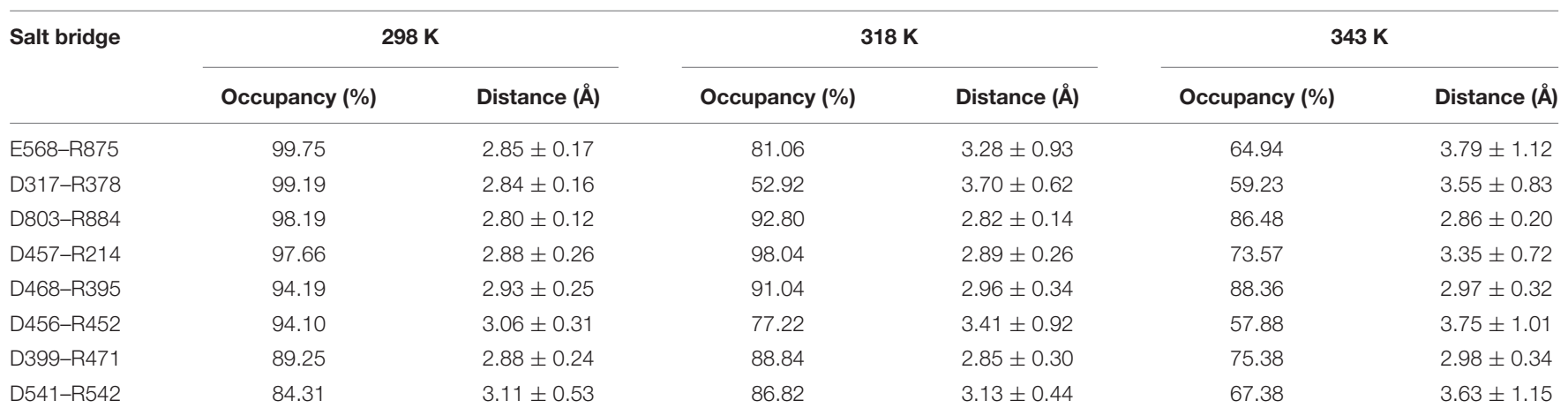




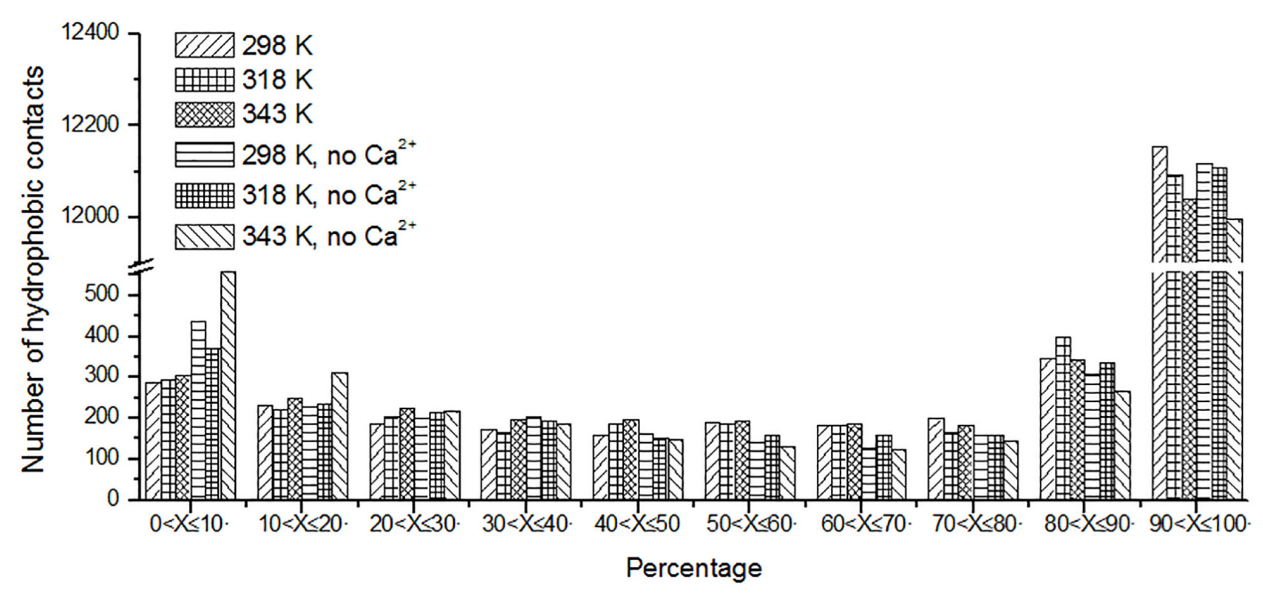

FIGURE 8 | The number of unique hydrophobic contacts based on the percentage existence time at cutoff of $4 \AA$.

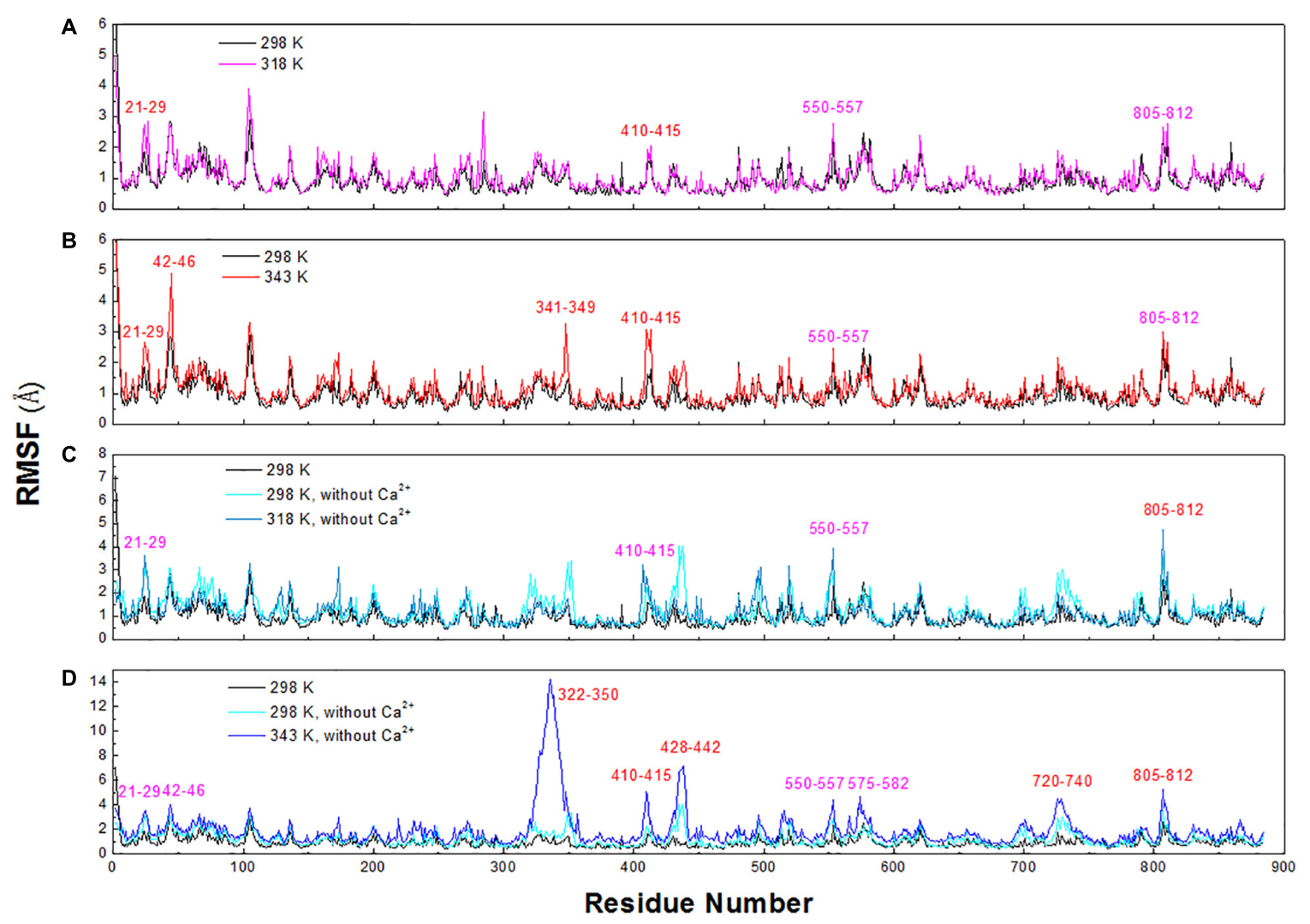

FIGURE 9 | RMSF plots of the backbone atoms of six systems. (A) 298 and 318 K. (B) 298 and 343 K. (C) Simulation at 298 and 318 K without Ca ${ }^{2+}$. (D) Simulation at 298 and $343 \mathrm{~K}$ without $\mathrm{Ca}^{2+}$.

salt bridges in thermophilic pullulan-hydrolyzing enzymes than mesophilic ones, suggesting the importance of salt bridge for the enzyme pullulan-hydrolyzing thermostability. In this work, the salt bridges were identified using a $4-\AA$ distance cutoff. We can observe that the number of short-lived salt bridges increases from 298 to $343 \mathrm{~K}$ (Figure 7), while the number of long-lived salt bridges decreases from 298 to $343 \mathrm{~K}$. It is indicated that the short-lived salt bridges form transiently at high temperature. Some long-lived salt bridges are broken at high temperature. The number of long-lived salt bridges also decreases in the systems without $\mathrm{Ca}^{2+}$, which suggests that ions $\mathrm{Ca}^{2+}$ contribute to the stability of salt bridges.

We also analyzed the salt bridges with occupancy higher than $50 \%$. The length of each salt bridge was averaged over 

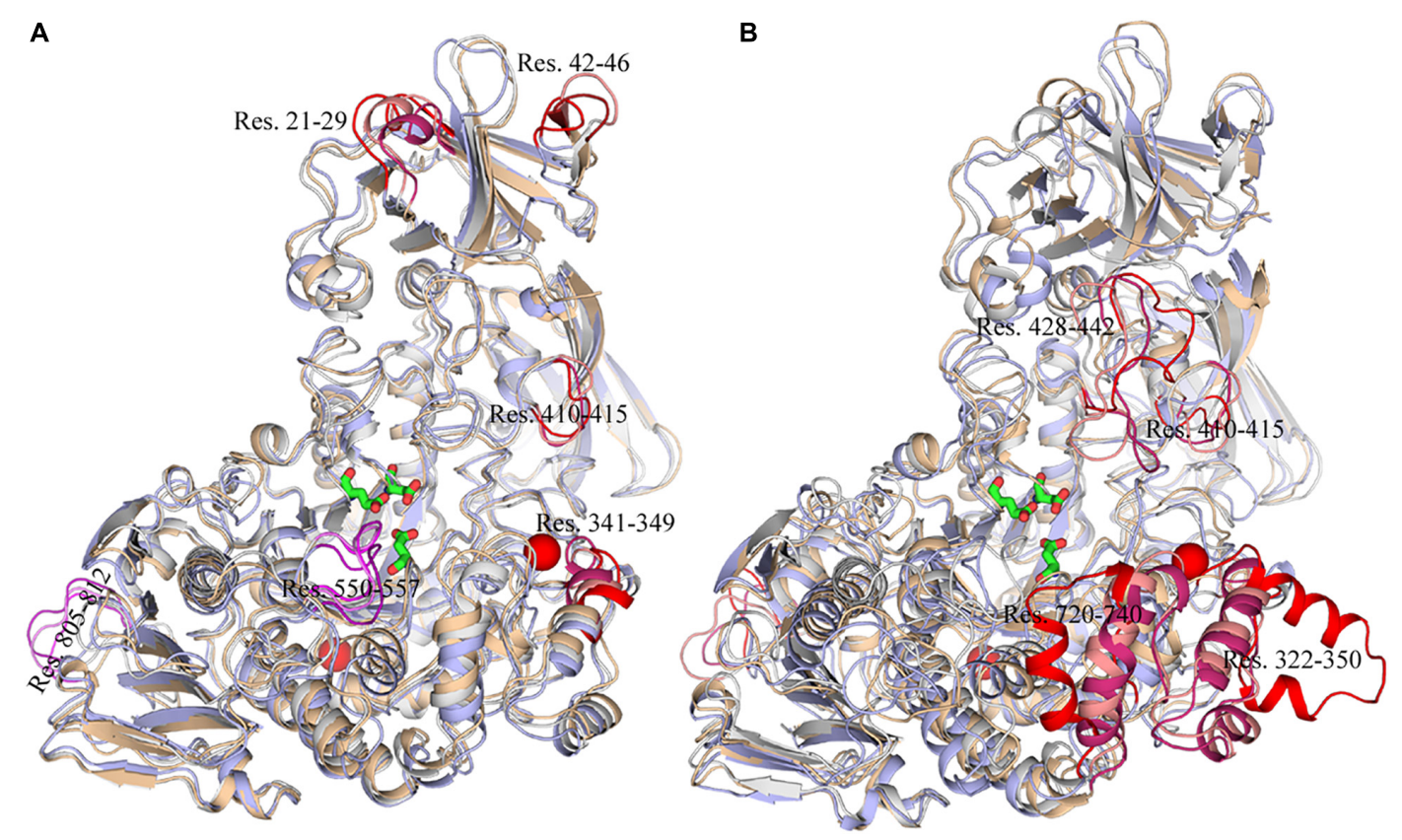

FIGURE 10 | Snapshots of HVLD structures from MD trajectories. (A) Comparison of the structure extracted from the system at 298, 318, and $343 \mathrm{~K}$, which are

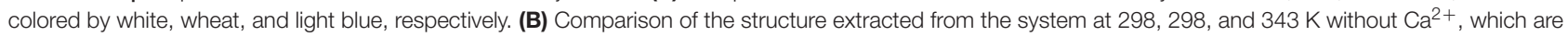
colored by white, wheat, and light blue, respectively. The high flexible region was colored by red.

the whole trajectory. There are 33, 30, and 29 salt bridges with occupancy higher than $50 \%$ during the simulations at 298 , 318 , and $343 \mathrm{~K}$ and 19 and 16 salt bridges in two systems without $\mathrm{Ca}^{2+}$ at 298 and $343 \mathrm{~K}$. The salt bridges are noted to decrease in number with an increase in temperature. There are 21 common salt bridges identified at 298,318 , and $343 \mathrm{~K}$. Among these salt bridges, five could still be maintained well even at high temperatures, suggesting an essential role in stabilizing this enzyme. There are eight salt bridges exhibiting comparable occupancy at three temperatures. These salt bridges were also not affected by increases in temperature. These 13 salt bridges are correlated with the partial structural stability of $H v \mathrm{LD}$, while 8 salt bridges become weak and their occupancy decreases with an increase in temperature (Table 4), including E568-R875, D317R378, D803-R884, D457-R214, D468-R395, D456-R452, D399$\mathrm{R} 471$, and D541-R542. These salt bridges are very sensitive to temperature changes and they affect the thermostability of $H v \mathrm{LD}$. All of the salt bridges are located on the surface of $H v \mathrm{LD}$.

To evaluate the function of salt bridge, the salt bridge between Asp317 and Arg378 was selected. The MD simulations on $\mathrm{LD}^{\mathrm{D} 317 \mathrm{~A}}$ at 298 and $343 \mathrm{~K}$ were conducted to evaluate the effect of salt bridge D317-R378 on the thermal stability of $H v \mathrm{LD}$. It is indicated that the break of this salt bridge destabilizes the protein. The $\mathrm{LD}^{\mathrm{D} 317 \mathrm{~A}}$ exhibited higher RMSD, $R_{\mathrm{g}}$, and SASA than $\mathrm{LD}^{\mathrm{WT}}$ at $298 \mathrm{~K}$ and $343 \mathrm{~K}$ (Supplementary Figure S1).

\section{Hydrophobic Contacts}

Protein stabilization is maintained by various interactions. Hydrophobic interaction is one of the important part of them (Van Dan Burg et al., 1994). Unique hydrophobic contacts were calculated as described in the "Materials and Methods" section. The percentage of time is displayed in Figure 8. It can be seen that the short-lived unique hydrophobic contacts $(0<X \leq 10 \%)$ increase from 298 to $343 \mathrm{~K}$. Long-lived hydrophobic contacts $(90<X \leq 100 \%)$ decrease from 298 to $343 \mathrm{~K}$. It exhibits the same trend with hydrogen bonds and salt bridges. A similar situation also occurs in systems without $\mathrm{Ca}^{2+}$.

\section{Identification of Thermal-Sensitive Regions}

To explore the structural and dynamic changes, we identified the thermal-sensitive regions of $H v \mathrm{LD}$ by analyzing the structural mobility based on the RMSF of the backbone atoms with respect to the initial structure. Figure 9 shows that the RMSF values of most regions of $H v \mathrm{LD}$ fluctuate slightly at a temperature of up to $343 \mathrm{~K}$, suggesting that these regions are relatively thermostable. Some regions showed steep RMSF fluctuations at high temperature, such as 318 and $343 \mathrm{~K}$, indicating that those are thermal-sensitive regions. It can be observed in Figure 9 that the highest fluctuations occur at the $\mathrm{N}$-terminal because it was not restrained. Also, some loops that always exhibit high fluctuation at different temperatures may be due to their intrinsic flexibility, including residues 102-107, 135-138, and 575-582. Besides, regions that fluctuated higher than 0.5 and $1.0 \AA$ are highlighted by magenta and red in Figure 9. Larger fluctuations are observed at $318 \mathrm{~K}$ or $343 \mathrm{~K}$, such as residues $21-29,42-$ $46,341-349$, and $410-415$. These regions are predicted to be thermal-sensitive regions. In a previous work, it was suggested that residues $23-27,42-48,102-109$, and 806-810 exhibited high 
flexibility, with low level electron density (Vester-Christensen et al., 2010), which is consistent with our results. To compare with those systems without $\mathrm{Ca}^{2+}$, it can be observed that the flexibility of LD is all higher in these systems than that at $298 \mathrm{~K}$. In particular, these loops exhibit high fluctuations, including residues 21-29, 42-46, 322-350, 410-415, 428-442, 550-557, 575-582, 720-740, and 805-812.

To exhibit these regions in $H v \mathrm{LD}$, the higher fluctuation regions were mapped onto the tertiary structure. As shown in Figure 10, it is observed that some of them are located near the catalytic crevice, including residues 550-557 (Figure 10A). The high flexibility of these regions would decrease the stability of the catalytic triad. Residues 21-29, 42-46, 341-349, and 410-415 are located in surface loops (Figure 10A). In the systems without $\mathrm{Ca}^{2+}$, there are large conformational change of residues 322-350, 428-442, 720-740, and 805-812 at high temperature $(343 \mathrm{~K})$ (Figure 10B). The loss of $\mathrm{Ca}^{2+}$ made the significant conformational change of a long loop in catalytic $(\beta / \alpha)$ eight domain, previously described as loop 2 (Jespersen et al., 1991; Mikami et al., 2006; Turkenburg et al., 2009) (the site for Ca1) (Supplementary Figure S2), indicating that this $\mathrm{Ca}^{2+}$ are important for maintaining the stable conformation of $H v \mathrm{LD}$ at high temperature. The conformational change of loop 2 affected the conformation of residue $322-350$ and 720-740. The removal of another $\mathrm{Ca}^{2+}$, which is located between $\alpha 1$ and $\alpha 2$, had a weaker effect on the conformation of $H v L D$ at different temperatures. This $\mathrm{Ca}^{2+}$ contributes less to the stability of $\mathrm{HvLD}$.

\section{CONCLUSION}

In the present study, thermostability factors of barley LD were investigated by MD simulations. The higher value of RMSD, $R_{\mathrm{g}}$, and SASA suggests the instability of $H v \mathrm{LD}$ at high temperatures. Intra-protein hydrogen bonds and hydrogen bonds between protein and water decrease at high temperature. Long-lived hydrogen bonds, salt bridges, and hydrophobic contacts are lost at high temperature. The salt bridge interaction analysis suggests that these salt bridges are important for the thermostability of $H v \mathrm{LD}$, including E568-R875, D317-R378, D803-R884, D457R214, D468-R395, D456-R452, D399-R471, and D541-R542, which are located on the surface of $H v \mathrm{LD}$. Based on RMSF calculations for $H v \mathrm{LD}$ at various temperatures, several thermally sensitive regions of $H v \mathrm{LD}$ were identified, such as residues 21-29,

\section{REFERENCES}

Alizadeh-Rahrovi, J., Shayesteh, A., and Ebrahim-Habibi, A. (2015). Structural stability of myoglobin and glycomyoglobin: a comparative molecular dynamics simulation study. J. Biol. Phys. 41, 349-366. doi: 10.1007/s10867-015-9383-2

Anandakrishnan, R., Aguilar, B., and Onufriev, A. V. (2012). H++ 3.0: automating $\mathrm{pK}$ prediction and the preparation of biomolecular structures for atomistic molecular modeling and simulations. Nucleic Acids Res. 40, W537-W541. doi: 10.1093/nar/gks375

Bradbrook, G. M., Gleichmann, T., Harrop, S. J., Habash, J., Raftery, J., Kalb, J., et al. (1998). X-Ray and molecular dynamics studies of concanavalin-A glucoside and mannoside complexes Relating structure to thermodynamics of binding. J. Chem. Soc. Faraday Trans. 94, 1603-1611. doi: 10.1039/A800429C
42-46, 341-349, and 410-415. The structural and dynamic details will help to understand the driving forces that lead to the stability of $H v \mathrm{LD}$ at different temperatures, which will facilitate enzyme engineering of $H v \mathrm{LD}$ for enhanced thermostability.

\section{DATA AVAILABILITY STATEMENT}

The raw data supporting the conclusions of this article will be made available by the authors, without undue reservation, to any qualified researcher.

\section{AUTHOR CONTRIBUTIONS}

JDu conceived and supervised the experiments. JDo, SD, and KZ performed the MD simulations. JDo, JDu, JY, and SH analyzed the data. JDu and HY wrote the manuscript.

\section{FUNDING}

This work was supported by the Open Research Fund of State Key Laboratory of Biological Fermentation Engineering of Beer (grant no. K201804), the Natural Science Foundation of Shandong Province, China (grant no. ZR2018QB004) and the Off-site collaborative calculation of marine medicinal biological resources (grant no. 2018ASKJ01-05).

\section{SUPPLEMENTARY MATERIAL}

The Supplementary Material for this article can be found online at: https://www.frontiersin.org/articles/10.3389/fmolb. 2020.00051/full\#supplementary-material

FIGURE S1 | RMSD, $R_{g}$, and SASA for HVLD ${ }^{D 17 A}$. (A) RMSD plot. (B) $R_{g}$ plot. (C) SASA plot.

FIGURE S2 | The conformation of Ca1 site. Initial structure and the extracted structure form system without $\mathrm{Ca}^{2+}$ at $343 \mathrm{~K}$ are colored by cyan and purple, respectively.

TABLE S1 | Statistical analysis results of RMSD, $R_{\mathrm{g}}$ and SASA for HVLD at different simulation temperatures.

TABLE S2 | Length and occupancy of important hydrogen bond interactions of HVLD at 298, 318, and $343 \mathrm{~K}$.

Chang, M., Chu, X., Lv, J., Li, Q., Tian, J., and Wu, N. (2016). Improving the thermostability of acidic pullulanase from bacillus naganoensis by rational design. PLoS One 11:e0165006. doi: 10.1371/journal.pone.0165006

Chen, A., Li, Y., Nie, J., McNeil, B., Jeffrey, L., Yang, Y., et al. (2015). Protein engineering of Bacillus acidopullulyticus pullulanase for enhanced thermostability using in silico data driven rational design methods. Enzyme Microb. Technol. 78, 74-83. doi: 10.1016/j.enzmictec.2015.06.013

Coleman, T. G., Mesick, H. C., and Darby, R. L. (1977). Numerical integration: a method for improving solution stability in models of the circulation. Ann. Biomed. Eng. 5, 322-328. doi: 10.1007/BF02367312

Darden, T., York, D., and Pedersen, L. (1993). Particle mesh Ewald: An N.log(N) method for Ewald sums in large systems. J. Chem.Phys. 98, 10089-10092. doi: $10.1063 / 1.464397$ 
Gu, J., Tong, H., Sun, L., and Lin, Z. (2019). Molecular dynamics perspective on the thermal stability of mandelate racemase. J. Biomol. Struct. Dyn. 37, 383-393. doi: 10.1080/07391102.2018.1427631

Guo, J., Coker, A. R., Wood, S. P., Cooper, J. B., Keegan, R. M., Ahmad, N., et al. (2018). Structure and function of the type III pullulan hydrolase from Thermococcus kodakarensis. Acta Crystallogr. Sec. D 74, 305-314. doi: 10.1107/ S2059798318001754

Hornak, V., Abel, R., Okur, A., Strockbine, B., Roitberg, A., and Simmerling, C. (2006). Comparison of multiple Amber force fields and development of improved protein backbone parameters. Proteins 65, 712-725. doi: 10.1002/ prot. 21123

Horovitz, A., Serrano, L., Avron, B., Bycroft, M., and Fersht, A. R. (1990). Strength and co-operativity of contributions of surface salt bridges to protein stability. J. Mol. Biol. 216, 1031-1044. doi: 10.1016/S0022-2836(99)80018-7

Humphrey, W., Dalke, A., and Schulten, K. (1996). VMD: Visual molecular dynamics. J. Mol. Graph. 14, 33-38. doi: 10.1016/0263-7855(96)00018-5

Idrees, D., Rahman, S., Shahbaaz, M., Haque, M. A., Islam, A., Ahmad, F., et al. (2017). Estimation of thermodynamic stability of human carbonic anhydrase IX from urea-induced denaturation and MD simulation studies. Int. J. Biol. Macromol. 105, 183-189. doi: 10.1016/j.ijbiomac.2017. 07.010

Jelesarov, I., and Karshikoff, A. (2009). "Defining the role of salt bridges in protein stability," in Protein Structure, Stability, and Interactions, ed. J. W. Shriver (Totowa, NJ: Humana Press), doi: 10.1007/978-1-59745-367-7_10

Jespersen, H. M., MacGregor, E. A., Sierks, M. R., and Svensson, B. (1991). Comparison of the domain-level organization of starch hydrolases and related enzymes. Biochem. J. 280, 51-55. doi: 10.1042/bj2800051

Jiang, X., Chen, G., and Wang, L. (2016). Structural and dynamic evolution of the amphipathic N-terminus diversifies enzyme thermostability in the glycoside hydrolase family 12. Phys. Chem. Chem. Phys. 18, 21340-21350. doi: 10.1039/ C6CP02998A

Jorgensen, W. L., Chandrasekhar, J., Madura, J. D., Impey, R. W., and Klein, M. L. (1983). Comparison of simple potential functions for simulating liquid water. J. Chem. Phys. 79, 926-935. doi: 10.1063/1.445869

Kundu, S., and Roy, D. (2010). Structural study of carboxylesterase from hyperthermophilic bacteria Geobacillus stearothermophilus by molecular dynamics simulation. J. Mol. Graph. Model. 28, 820-827. doi: 10.1016/j.jmgm. 2010.03.001

Li, S., Xu, J., Bao, Y., Zheng, H., and Song, H. (2015). Structure and sequence analysis-based engineering of pullulanase from Anoxybacillus sp. LM18-11 for improved thermostability. J. Biotechnol. 210, 8-14. doi: 10.1016/j.jbiotec.2015. 06.406

Manners, D. J., Marshall, J. J., and Yellowlees, D. (1970). The specificity of cereal limit dextrinases. Biochem. J. 116, 539-541. doi: 10.1042/bj1160539

Mikami, B., Iwamoto, H., Malle, D., Yoon, H.-J., Demirkan-Sarikaya, E., Mezaki, Y., et al. (2006). Crystal structure of pullulanase: evidence for parallel binding of oligosaccharides in the active site. J. Mol. Biol. 359, 690-707. doi: 10.1016/j. jmb.2006.03.058

Møller, M., Hachem, M. Abou, Svensson, B., and Henriksen, A. (2012a). Structure of the starch-debranching enzyme barley limit dextrinase reveals homology of the N-terminal domain to CBM21. Acta Crystallogr. Sect. F Struct. Biol. Cryst. Commun. 68(Pt 9), 1008-1012. doi: 10.1107/S1744309112031004

Møller, M. S., Abou Hachem, M., Svensson, B., and Henriksen, A. (2012b). Structure of the starch-debranching enzyme barley limit dextrinase reveals homology of the N-terminal domain to CBM21. Acta Crystallogr. 68(Pt 9), 1008-1012.

Møller, M. S., Vester-Christensen, M. B., Jensen, J. M., Hachem, M. A., Henriksen, A., and Svensson, B. (2015a). Crystal Structure of Barley Limit Dextrinase-Limit Dextrinase Inhibitor (LD-LDI) Complex Reveals Insights into Mechanism and Diversity of Cereal Type Inhibitors. J. Biol. Chem. 290, 12614-12629. doi: 10. 1074/jbc.M115.642777

Møller, M. S., Windahl, M. S., Sim, L., Bøjstrup, M., Abou Hachem, M., Hindsgaul, O., et al. (2015b). Oligosaccharide and Substrate Binding in the Starch Debranching Enzyme Barley Limit Dextrinase. J. Mol. Biol. 427(6 Pt B), $1263-$ 1277. doi: 10.1016/j.jmb.2014.12.019

Moshi, A. P., Hosea, K. M. M., Elisante, E., Mamo, G., and Mattiasson, B. (2015). High temperature simultaneous saccharification and fermentation of starch from inedible wild cassava (Manihot glaziovii) to bioethanol using Caloramator boliviensis. Bioresour. Technol. 180, 128-136. doi: 10.1016/j.biortech.2014. 12.087
Nick Pace, C., Scholtz, J. M., and Grimsley, G. R. (2014). Forces stabilizing proteins. FEBS Lett. 588, 2177-2184. doi: 10.1016/j.febslet.2014.05.006

Nilofer, C., Sukhwal, A., Mohanapriya, A., and Kangueane, P. (2017). Proteinprotein interfaces are vdW dominant with selective $\mathrm{H}$-bonds and (or) electrostatics towards broad functional specificity. Bioinformation 13, 164-173. doi: 10.6026/97320630013164

Roe, D. R., and Cheatham, T. E. (2013). PTRAJ and CPPTRAJ: software for processing and analysis of molecular dynamics trajectory data. J. Chem. Theor. Comput. 9, 3084-3095. doi: 10.1021/ct400341p

Schrödinger, L. L. C. (2010). The PyMOL Molecular Graphics System, Version 1.3.1. The PyMOL Molecular Graphics System, Version 1.3.1.

Sharma, R., and Sastry, G. N. (2015). Deciphering the dynamics of non-covalent interactions affecting thermal stability of a protein: molecular dynamics study on point mutant of thermus thermophilus isopropylmalate dehydrogenase. PLoS One 10:e0144294. doi: 10.1371/journal.pone.0144294

Sissons, M., Taylor, M., and Proudlove, M. (1995). Barley malt limit dextrinase: Its extraction, heat stability, and activity during malting and mashing. Am. Soc. Brew. Chem. 21, S356.

Sissons, M. J., Lance, R. C. M., and Wallace, W. (1994). Bound and free forms of barley limit dextrinase. Cereal Chem. 71, 520-521.

Stam, M. R., Danchin, E. G. J., Rancurel, C., Coutinho, P. M., and Henrissat, B. (2006). Dividing the large glycoside hydrolase family 13 into subfamilies: towards improved functional annotations of $\alpha$-amylase-related proteins. Protein Eng. Design Select. 19, 555-562. doi: 10.1093/protein/gzl044

Stojanovic, S. D., and Zaric, S. D. (2009). Hydrogen bonds and hydrophobic interactions of porphyrins in porphyrin-containing proteins. Open Struct. Biol. J. 3, 34-41. doi: 10.2174/1874199100903010034

Strop, P., and Mayo, S. L. (2000). Contribution of surface salt bridges to protein stability. Biochemistry 39, 1251-1255. doi: 10.1021/bi992257j

Turkenburg, J. P., Brzozowski, A. M., Svendsen, A., Borchert, T. V., Davies, G. J., and Wilson, K. S. (2009). Structure of a pullulanase from Bacillus acidopullulyticus. Proteins 76, 516-519. doi: 10.1002/prot.22416

Van Dan Burg, B., Dijkstra, B. W., Vriend, G., Van Dar Vinne, B., Venema, G., and Eijsink, V. G. H. (1994). Protein stabilization by hydrophobic interactions at the surface. Eur. J. Biochem. 220, 981-985. doi: 10.1111/j.1432-1033.1994.tb18702.x

Vester-Christensen, M. B., Hachem, M. A., Svensson, B., and Henriksen, A. (2010). Crystal structure of an essential enzyme in seed starch degradation: barley limit dextrinase in complex with cyclodextrins. J. Mol. Biol. 403, 739-750. doi: 10.1016/j.jmb.2010.09.031

Vieille, C., and Zeikus, G. J. (2001). Hyperthermophilic enzymes: sources, uses, and molecular mechanisms for thermostability. Microbiol. Mol. Biol. Rev. 65, 1-43. doi: $10.1128 / \mathrm{mmbr} .65 .1 .1-43.2001$

Wang, J., Wolf, R. M., Caldwell, J. W., Kollman, P. A., and Case, D. A. (2004). Development and testing of a general amber force field. J. Comput. Chem. 25, 1157-1174. doi: 10.1002/jcc.20035

Wang, X., Nie, Y., Mu, X., Xu, Y., and Xiao, R. (2016). Disorder prediction-based construct optimization improves activity and catalytic efficiency of Bacillus naganoensis pullulanase. Sci. Rep. 6:24574. doi: 10.1038/srep24574

Wang, X., Zhang, X., Cai, S., Ye, L., Zhou, M., Chen, Z., et al. (2015). Genetic diversity and QTL mapping of thermostability of limit dextrinase in barley. J. Agric. Food Chem. 63, 3778-3783. doi: 10.1021/acs.jafc.5b00190

Yang, X., Westcott, S., Gong, X., Evans, E., Zhang, X.-Q., Lance, R. C. M., et al. (2008). Amino acid substitutions of the limit dextrinase gene in barley are associated with enzyme thermostability. Mol. Breed. 23, 61. doi: 10.1007/ s11032-008-9214-2

Conflict of Interest: JDu, JDo, JY, SH, and HY were employed by company Tsingtao Brewery.

The remaining authors declare that the research was conducted in the absence of any commercial or financial relationships that could be construed as a potential conflict of interest.

Copyright (C) $2020 \mathrm{Du}$, Dong, Du, Zhang, Yu, Hu and Yin. This is an open-access article distributed under the terms of the Creative Commons Attribution License (CC BY). The use, distribution or reproduction in other forums is permitted, provided the original author(s) and the copyright owner(s) are credited and that the original publication in this journal is cited, in accordance with accepted academic practice. No use, distribution or reproduction is permitted which does not comply with these terms. 